\title{
New insights from speciation analyses \\ on trace metal oxyanion geochemistry in modern and ancient sulfidic settings
}

\section{ANTHONY CHAPPAZ}

STARLAB- Central Michigan University

Presenting Author: anthony.c@cmich.edu

Trace metal oxyanions are a particular type of redox sensitive elements because their presumed stable form in oxygenated waters is composed by a central metal cation $\left(\mathrm{Me}^{\mathrm{Z}+}\right)$ surrounded either by oxygen atoms $(-\mathrm{O})$, hydroxyl molecules $(-\mathrm{OH})$, or a combination of both $(-\mathrm{OOH})$ acting as anionic ligands. General formulas can either be $\mathrm{MeO}_{\mathrm{x}}^{(\mathrm{z}-\mathrm{x})-}$ or $\mathrm{Me}(\mathrm{OH})_{\mathrm{x}}^{(\mathrm{z}-\mathrm{x})-}$. In this keynote I will give an update on our understanding of the geochemical controls involved in the burial pathways of molybdenum (Mo), rhenium (Re), chromium $(\mathrm{Cr})$ and vanadium (V) in sulfidic settings. More particularly I will discuss the role of sulfide S(-II), iron-sulfur mineral and organic matter phases, independently but also concomitantly. A particular emphasize will be given to the importance of characterizing the speciation of trace metal oxyanions as it pertains to their reactivity and therefore ultimately to their sinks. 